\title{
0 que é mais importante vem primeiro
}

\author{
Resenha de Justificação e crítica: Perspectivas de \\ uma teoria crítica da política, de Rainer Forst (São \\ Paulo: Unesp, 2018)
}

\author{
Felipe Moralles e Moraes \\ felipe.moralles@gmail.com \\ (Universidade Federal de Santa Catarina, Santa Catarina, Brasil)
}

DOI: http://dx.doi.org/10.11606/issn.2318-9800.v24i1p173-181

Rainer Forst é um dos mais proeminentes representantes contemporâneos da teoria crítica da Escola de Frankfurt. Em seu dizer - oportunamente reproduzido na contracapa da edição brasileira publicada recentemente pela Unesp e cuidadosamente traduzida por Denilson Luis Werle -, a filosofia crítica começa com uma tentativa de evitar os "becos sem saída" nos quais a própria filosofia política vem se metendo. A tarefa que se coloca esse discípulo de Habermas é, como explicado no prefácio, desfazer os dualismos enganadores. À primeira vista, o livro Justificação e crítica consiste em uma reunião de artigos publicados anteriormente, em diferentes locais e sem sistematicidade, como os três capítulos finais que discutem a obra de Henrik Ibsen, Hannah Arendt e a literatura utópica. Há um fio condutor dos artigos reunidos, porém, que é enfrentar falsas oposições, como entre imanência e transcendência; dominação e liberdade; igualitarismo e suficientarianismo; paz e justiça; iluminismo e pós-colonialismo; redistribuição e reconhecimento; a fim de defender que, por trás delas, há algo mais importante, que é o direito fundamental à justificação.

A linhagem kantiana da crítica de Forst é notável. À sua época, Kant tinha por alvo a oposição entre, por um lado, o ceticismo, com sua tese da impossibilidade do conhecimento universal e necessário sobre o mundo; e, por outro lado, o dogmatismo metafísico, com sua pretensão de decifrar o mundo a partir da razão pura. É conhecida a solução kantiana de rejeitar o tribunal tanto da natureza sensível (empirismo), quanto de um ser, bem ou valor superior ao sujeito (racionalismo dogmático), para alçar a razão como o tribunal do uso legítimo e ilegítimo de suas faculdades (racionalismo crítico). A filosofia crítica continua merecendo seu nome na medida em que denuncia as ilusões para as quais é arrastada a razão no interesse emancipatório 
de conhecer o mundo e agir corretamente.

A tarefa kantiana de Forst não se limita, contudo, a desmascarar essas ciladas da razão, como também faziam, cada um a seu modo, Marx e as primeiras gerações da Escola de Frankfurt. Há um objetivo maior em comparação com esses críticos da modernidade: colocar a razão ao abrigo dos ataques céticos e dogmáticos. Por isso, uma segunda tarefa filosófica que permeia Justificação e crítica é a de fundamentação dos direitos humanos e da justiça. A obra complementa análises precedentes de Forst, nas quais o autor reconstrói e busca superar as aporias do debate entre liberalismo e comunitarismo, em Contextos da justiça, com edição brasileira pela editora Boitempo (2010 [1994]), ou apresenta uma concepção construtivista moral e política da justiça e dos direitos humanos, em Direito à justificação, ainda sem tradução (2012[2007]). Nesta resenha, contento-me em apresentar (1) a resolução forstiana de dois impasses internos à teoria crítica e (2) a fundamentação trazida em Justificação e crítica (daqui em diante JC), para depois tecer (3) alguns comentários sobre a tradução e (4) levantar quatro possíveis objeções ao modelo de teoria crítica em questão.

1. 0 primeiro impasse enfrentado por Forst diz respeito à ideia de crítica imanente da sociedade, que os teóricos críticos tradicionalmente contrastaram com o que seriam críticas transcendentes, platônicas ou idealizadas. 0 argumento do autor é que essa contraposição mostra-se ilusória, porque ninguém está totalmente inserido em um contexto ou prática social, havendo sempre possibilidade de questionar e criticar reflexivamente essa prática. Os conflitos sociais surgem, com efeito, com um "não" às formas de justificação da dominação existente. Eles estão sempre questionando e transcendendo costumes, relações econômicas e instituições. Assim, se consideramos os seres humanos como seres que participam ativamente na definição das relações e ordens sociais válidas, estamos diante de um padrão a um só tempo imanente e transcendente. A recusa às justificações vigentes pode ser traduzida como uma pretensão de que as relações sociais não sejam arbitrárias, isto é, que sejam justificadas recíproca e universalmente. Segundo Forst, a razão é, ao mesmo tempo, a mais imanente e a mais transcendente das capacidades humanas: a capacidade de se orientar por justificações. A crítica da sociedade precisa se orientar pelo critério da reciprocidade e da universalidade das justificações, em lugar da divisão artificial entre imanência e transcendência (JC, p. 17-8). ${ }^{1}$

Outro impasse na teoria crítica que merece destaque está na discussão entre duas gramáticas internas às lutas sociais: redistribuição ou reconhecimento. Tratase de uma disputa em vários níveis, encabeçada por Nancy Fraser e Axel Honneth. Ambas gramáticas são indeterminadas do ponto de vista de quais lutas sociais são justificáveis - argumenta Forst. Antes da pretensão por paridade de participação,

1 Essa questão vai ser retomada na obra mais recente de Forst (2015a, p. 13-5). 
no modelo de Fraser (duplipartido em redistribuição e reconhecimento), ou da pretensão por reconhecimento, no modelo de Honneth (tripartido nas esferas do amor, da igualdade jurídica e da estima social), é preciso uma gramática normativa que diferencie as pretensões justificáveis das injustificáveis, isto é, aquelas que podem, ou não, ser justificadas de modo recíproco e universal aos que participam nos respectivos contextos de justiça (JC, p. 185 e 192). É certo que, conforme o contexto, surgirão pretensões legítimas de igualdade econômica e política ou de valorização social; primeiro, porém, vem a instância da possibilidade de produzir e questionar essas pretensões. A gramática normativa é a das condições para que os sujeitos se justifiquem e demandem justificações: o direito básico à justificação. A abordagem de Forst é denominada, por isso, "o que é mais importante vem primeiro" - na feliz tradução de das Wichtigste zuerst ou first-things-first da edição inglesa (2014). Ele afirma dar uma "guinada política" diante das abordagens antecedentes, ao colocar em primeiro plano exercício e distribuição social do poder de justificação (JC, p. 196).

Daí repetir Forst nos artigos que a tarefa primeira de uma teoria crítica da justiça é visar ao estabelecimento de uma estrutura básica de justificação na qual as pessoas possuam procedimentos e condições materiais de exigir, produzir e questionar justificações - o que não se confunde, nem exclui, a perspectiva mais utópica de uma estrutura básica justificada, na qual todos os procedimentos e condições materiais foram justificados universal e reciprocamente. Isso lhe permite dar um passo atrás nas disputas entre modelos de justiça distributiva (pois o poder de justificação sobre as estruturas de produção e distribuição antecede a discussão sobre o que será distribuído - recursos, bem-estar ou capabilities); na tensão entre paz e direitos humanos (porque ambos estão subordinados a um princípio de justiça, que reivindica a entrada no domínio das justificações recíprocas e se contrapõe às injustiças que acompanham conflitos violentos); nas críticas feministas, negras e pós-coloniais contra machismo, etnocentrismo e iluminismo (que se apoiam na exigência de uma justificação aceitável para todos, de modo que é a própria justiça a tornar visível sua realização imperfeita). ${ }^{2}$

2. A fundamentação forstiana do direito fundamental à justificação diferenciase da fundamentação kantiana, porque se baseia, em lugar de uma razão prática pura, em uma razão que se efetiva contextualmente na forma de justificações. Ela pode ser resumida do seguinte modo. Toda crítica pressupõe a recusa à arbitrariedade. $\mathrm{E}$ entende-se como arbitrária qualquer relação que não possa ser razoavelmente aceita por todos os concernidos. Acontece que interesses básicos humanos podem sempre abrigar arbitrariedades. Vínculos afetivos, sentimentos de pertença ou concepções

2 Sobre esse último ponto, ver especialmente os argumentos de Forst contra as críticas feministas à ideia de pessoa de direito e às linguagens políticas universalistas (1994, p. 117-123 e 199-209). 
de vida boa (como as emergentes em uma cultura machista, racista, eurocêntrica, por exemplo) podem ser razoavelmente recusados por outras pessoas. Logo, uma perspectiva crítica da sociedade não consegue fundamento racional em interesses humanos básicos. Para Forst, a razão deveria ser compreendida não como um interesse humano básico, mas pura e simplesmente como justificação discursiva. Uma relação deixa de ser arbitrária, então, se ela pode ser justificada discursivamente para todos os concernidos. Logo, a crítica da sociedade pressupõe um poder de todos de exigir, produzir e questionar justificações na sociedade: um direito universal à justificação. A justiça (entendida como negação da arbitrariedade) e os direitos humanos (entendidos como direitos de não se sujeitar ao arbítrio de outrem) têm fundamento nesse direito básico à justificação.

Com essa fundamentação, Forst sublinha que os seres humanos não são seres passivos, necessitados e sofredores, mas sim reivindicam reconhecimento como sujeitos reflexivos e autônomos. Eles não somente participam de relações sociais, normas e instituições que constantemente reivindicam validade, mas também examinam suas justificações, as rejeitam e redefinem. Daí falar de relações sociais como ordens de justificação. A justificação efetiva que legitima e constitui as relações de poder é comparada, em meio aos conflitos sociais, com a justificação devida - que tem a qualidade de ser recíproca e universal. Essa vinculação entre justificações dadas e devidas; entre ordens produzidas por justificações e obstáculos ao direito fundamental à justificação; em suma, entre descrição e normatividade dá-se por meio (i) da descoberta das relações sociais que não podem ser justificadas recíproca e universalmente, (ii) da crítica às justificações falsas ou ideológicas, no sentido de um bloqueio ao direito à justificação, e (iii) da explicação do fracasso ou ausência de estruturas efetivas de justificação (JC, p. 195-6). Nesse sentido, permanece ele no interior da "velha questão de por que a sociedade moderna não está em condições de produzir formas racionais de ordem social", ou seja, da investigação de por que as ordens de justificação se tornam dominações arbitrárias (JC, p. 20-1).

3. Antes de adentrar nas possíveis críticas, três breves questões sobre a tradução.

Werle conserva a tradição da sociologia weberiana de traduzir Herrschaft como "dominação", a qual aproxima as noções de dominação e legitimidade. Toda forma de dominação é legítima, na medida em que se entenda o conceito de legitimidade em um sentido estritamente descritivo, sem sobrepor um sentido normativo e crítico, como prioriza Forst: a qualidade de uma ordem normativa de explicar e justificar seu poder vinculativo geral aos seus subordinados (2015a, p. 189). Diferentemente da tradição weberiana, porém, Forst distingue a forma neutra (e possivelmente justa) Herrschaft da forma injusta Beherrschung (JC, p. 27). Para reproduzir no português, seria necessário algo como a distinção entre "domínio" e "dominação", 
não tão intuitiva ao leitor e que pouco contribuiria para a clareza da argumentação. Andou bem o tradutor, pois, em se manter fiel à tradição e traduzir Herrschaft e Beherrschung respectivamente como “dominação" e “dominação arbitrária”.

Uma opção que também merece comentário é a tradução da necessidade de um consentimento baseado em procedimentos de justificação institucionalizados e, ao mesmo tempo, em um sentido contrafactual, de modo recíproco e universal, com a expressão "no modo subjuntivo” (JC, p. 51 e 141). Diferente dos equiparáveis im Konjunktiv e konjunktivisch utilizados por Forst, que remetem mais diretamente, na língua alemã, à situação irreal, o subjuntivo da língua portuguesa é um modo verbal que tem vários tempos, dos quais só o pretérito representa um modo contrafactual. Acredito que, novamente se distanciando do original, mais clara seria a expressão "no modo contrafactual”, como na tradução inglesa (2014, p. 34 e 83). O consentimento é contrafactual porque a pretensão normativa mostra-se válida moralmente na medida em que não lhe podem ser opostas justificações gerais e recíprocas. A pretensão normativa não é rejeitável, o que independe de um consenso ou aceitação efetiva (2012[2007], p. 21).

Uma opção mais polêmica é a tradução da concepção de pessoa de Forst als begründendes, rechtfertigendes Wesen, isto é, como um ser fundamentador e justificador, em termos menos carregados: "como sujeito que fundamenta e justifica" (JC, p. 159). Essa opção oferece mais consistência à argumentação, ao custo de minimizar a pretensão antropológica de Forst, como se verá a seguir.

4. O aspecto desconcertante da obra - ou "irritante" para usar a tradução preferida nessa edição (JC, p. 135) - é sua vinculação ao individualismo metodológico: a argumentação parte de conceitos a priori, do "a priori da justificação" (JC, p. 192), em detrimento da análise social e histórica das relações de justificação. Essa análise até aparece no texto, mas só a título de ilustração. Tal ponto foi levantado por Rúrion Melo em sua crítica ao construtivismo moral de Forst: a praxis da justificação fundase em pressupostos morais que independem da gênese histórica e política e que não oferecem um diagnóstico de época de como as reivindicações por justiça tornam-se reivindicações por respeito aos sujeitos de justificação (2013, p. 26-8). O aspecto metodológico não desmerece, no entanto, os objetivos traçados por Forst de afastar dualismos enganadores e de fundamentar o projeto de uma teoria crítica da justiça.

$\mathrm{Na}$ dimensão da ontologia social reside um problema mais grave para a teoria crítica defendida pelo autor. A teoria do direito à justificação não contém só uma tese sobre o domínio da teoria crítica da política (devemos investigar a distribuição do poder de justificação na sociedade), mas também uma tese ontológica (as esferas sociais são ordens de justificação). A questão que se coloca é se não bastaria, em lugar da tese ontológica, uma tese, por assim dizer, sociológica (há uma relação necessária entre esferas sociais e relações de justificação). Soa bastante implausível, 
com efeito, que todos os fenômenos de dominação operem no interior de ordens de justificação. Ainda que tais ordens existam, estão envolvidas por poderes anônimos - como autovalorização do capital, incremento da técnica, massificação social -, que conservariam sua intensidade mesmo diante de uma estrutura básica de justificação. O que sempre causou perplexidade na modernidade foi por que tantas pessoas se identificam com a desigualdade e a dominação arbitrária e deixam de questionálas. Seus grilhões não são de ferro, mas imaginários. Que todos tivessem garantias de exigir justificativas dos demais não significa que os poderes sistêmicos seriam amplamente questionados. Se a justificação permanecesse potencialmente aberta, esses poderes ainda não desmoronariam como tais, não ficariam vulneráveis, nem seriam desmascarados como injustificáveis, porque continuariam produzindo, de modo massivo e duradouro, bloqueios à atividade crítica. Daí a dificuldade de pensar em uma primazia ontológica da justificação.

A questão acerca da ontologia social surge sempre e novamente diante das tentativas de compreender a sociedade com base em um eixo único - como acontece comumente em relação ao sistema capitalista (cf. Dardot \& Laval, 2016, p. 31 e 3845; Jaeggi, 2015, p. 15) ou à ideia de liberdade (cf. Honneth, 2011, p. 9 e 35-40). Não é preciso supor metafisicamente, como ainda é comum entre os teóricos críticos, que todas esferas sociais e todos valores da sociedade moderna estejam fundidos em uma lógica, valor ou razão. No caso da teoria crítica de Forst, não é possível ignorar que há ordens que não se estabelecem por justificações, senão por seu bloqueio sistemático. Mais plausível parece supor uma relação necessária entre as esferas sociais e as justificações, mas sem excluir a relação concomitante com estruturas que impedem que as esferas sociais sejam planejadas, controladas ou direcionadas por razões. É o que sinaliza Forst ao mencionar os complexos de justificação ideológica, que naturalizam a dominação e se esquivam de questionamento crítico (JC, p. 170). Poderes sistêmicos parecem ser ordens que dependem necessariamente de justificações, mas que dependem delas de uma forma necessariamente preconfigurada e entravada, o que impede a abolição, ou mesmo reforma dessas ordens. Por isso, a dominação sistêmica antes determina justificações do que é por elas determinada. ${ }^{3}$

Ao responder a críticas contra seu conceito de poder, Forst vai admitir a necessidade de distinguir a dominação relacional da estrutural, insistindo, então, na conexão que existe entre essas estruturas e a produção de justificações e ações dos que se beneficiam delas ou dos que poderiam modificá-las: "nós devíamos nos livrar da oposição não-dialética entre considerações de poder estruturais ou entre agentes [inter-agential], porque claramente precisamos de ambas" (2018, p. 303). ${ }^{4}$ A sociedade moderna parece estruturada tanto em ordens de justificação, quanto

3 Devo essa ideia de poder sistêmico a conversa com José Ivan Rodrigues de Sousa Filho.

4 Sobre isso, ver respostas a Steven Lukes, Clarissa Hayward e Albena Azmanova (2018). 
em ordens sistêmicas, mesmo que entre elas subsista uma relação necessária, que se poderia chamar, mais convincentemente, liames de justificação, muito mais frágeis. Isso significa recusar a ontologia social monista de Forst e retornar a uma relação dualista, entre mundo da vida e sistema, como desenvolvido por Habermas (1995[1981]).

Essa crítica à pretensão ontológica da teoria de Forst não afeta, contudo, a abordagem defendida. A preocupação do filósofo alemão é que o direito à justificação precisa considerar o que há de racional na história e manter a distinção entre lutas sociais emancipatórias e não-emancipatórias, entre justificações boas e ideológicas, que é a pressão pela reciprocidade e universalidade adentrando todas esferas sociais, aí compreendidas as esferas de dominação sistêmica (2015c, p. 52-3). 0 direito à justificação não requer a tese extravagante de que todas as esferas sociais são realmente ordens de justificação. Em suas palavras:

Isso é uma razão importante para separar a análise, primeiro, sobre o exercício de poder entre agentes da análise, segundo, sobre formas estruturais de poder que expressam, constrangem e permitem tais formas de poder e, terceiro, do caráter e formação de recursos inteligíveis [noumenal] ou condições de fundo que levam e suportam essas estruturas, especialmente as narrativas de justificação em que se apoiam (2018, p. 306).

Além da crítica ao sentido ontológico da teoria do direito à justificação, é preciso acrescentar uma crítica à sua pretensão antropológica (os seres humanos são seres justificadores), a qual está no centro do argumento da obra Direito à Justificação (cf. 2007, p. 13 e 38-9) e é reproduzida nos trabalhos mais recentes (cf. 2018, p. 317-8). Não que a imagem de uma sociedade plenamente transparente e baseada em conteúdos e razões não rejeitáveis razoavelmente entre indivíduos dotados de um direito igual à justificação seja vaga e idealista, que ela abstraia das relações sociais ou que tome os sujeitos como unidades atomizadas. Nada disso. Afinal, as justificações dadas são sempre aqui e agora, conforme a situação e os conflitos reais, envoltas e obscurecidas por emoções, ideologias, ameaças; e as justificações devidas são aquelas voltadas pragmaticamente ao estabelecimento de uma estrutura básica de justificação (JC, p. 143). ${ }^{5}$ A questão que se coloca é se a ideia normativa de um direito individual à justificação volta a ser escorada em um interesse básico humano.

Em vez de o direito fundamental à justificação ser apresentado somente como condição de possibilidade para qualquer discurso crítico, cai-se na tentação de justificar a justificação. Forst invoca a natureza humana para justificar o dever de reconhecer os outros como seres justificadores, em outras palavras, como seres que usam e necessitam de justificações (JC, p. 159). A carência por justificações e a

\footnotetext{
5 Forst insiste nesses pontos ao responder às críticas de que sua teoria seria ingênua e racionalista quanto às motivações humanas, ou excessivamente vaga e abstrata quanto à determinação dos direitos humanos, como acusam Seyla Benhabib (2015b), Simone Chambers (2015c), Simon Susen, Steven Lukes, Mark Haugaard e Matthias Kettner (2018).
} 
capacidade de as produzir, exigir e questionar são convertidas em um direito moral, embora possam ser tão arbitrárias quanto qualquer outra carência ou capacidade. A questão é saber se a argumentação forstiana prescinde desse fundamento. De fato, não é necessário vincular o direito à justificação a uma antropologia. Em Justificação e crítica, Forst parte de que não uma capacidade ou carência humana, mas um princípio moral representa o critério último para julgar sobre a legitimidade das relações sociais. A tradução brasileira tem razões, pois, para minimizar o apelo ao ser justificador. Evita-se confundir o fundamento moral do direito à justificação seja com o fundamento em capacidades e carências humanas, seja com o fundamento em uma concepção de vida boa (a vida autônoma e reflexiva), do qual Forst busca se distanciar (JC, p. 90 e 105).

A maneira de conectar a dimensão moral da justificação aos demais contextos da justiça vem a reboque, ainda assim, das pretensões ontológica e antropológica, das quais se tentou resguardar até aqui a teoria crítica de Forst. 0 direito de recusar razões não-recíprocas e não-universais tem como objeto "toda ação ou norma que pretende ser legítima", em uma "teoria abrangente dos direitos humanos" (JC, p. 111). Acontece que, salvo a dimensão moral, as razões para agir não são recíprocas e universais. A justificação das ações individuais é incapaz, na maioria dos casos, de generalização, pois depende de premissas éticas, econômicas, jurídicas ou políticas compartilhadas, sem as quais não há ação justificada. Nesse aspecto, Seyla Benhabib tem razão em apontar que reciprocidade e universalidade funcionam para justificar deveres perfeitos, em uma estrutura básica de justificação, não deveres imperfeitos. É incompreensível como tais critérios poderiam guiar agentes individuais na justificação discursiva de suas ações éticas, políticas, jurídicas e econômicas (2015, p. 5-7). Respondendo, Forst exemplifica que a reciprocidade exclui o apelo a verdades religiosas ou à vontade da maioria para proibir a construção de minaretes ou o uso de vestes religiosas pelas mulheres (2015b, p. 50), o que está correto; todavia, a reciprocidade nada esclarece se o patrimônio urbanístico deve ter preferência à construção de templos, se certas vestes devem ter primazia à igualdade de gênero, quer dizer, acerca de conflitos entre valores e razões diferentes e irreconciliáveis. As dificuldades emergem na medida em que o direito à justificação seja alçado a uma teoria moral abrangente, capaz de regular todas as ações que tocam outras pessoas, em vez de uma teoria política, no sentido rawlsiano do termo (2005[1993], I, §2).

Nenhuma dessas críticas obscurece o que se pode reconhecer como avanços importantes na teoria crítica contemporânea, em razão do esforço de Forst de "limpar o terreno" dos "entulhos conceituais" acumulados nas controvérsias sobre esse modo de fazer filosofia. Trata-se de uma obra incontornável para todos que se engajam na tarefa de fazer um diagnóstico das sociedades contemporâneas do ponto de vista emancipatório, isso quer dizer, da justiça. 


\section{Referências}

Benhabib, S. (2015). The uses and abuses of Kantian rigorism. On Rainer Forst's moral and political philosophy. Political Theory, 43 (6), pp. 1-16.

Dardot, P., \& Laval, C. (2016). A nova razão do mundo: Ensaio sobre a sociedade neoliberal [2009]. Tradução de Mariana Echalar. São Paulo, SP: Boitempo.

Forst, R. (1994). Kontexte der Gerechtigkeit: Politische Philosophie jenseits von Liberalismus und Kommunitarismus. Frankfurt am Main: Suhrkamp.

(2010). Contextos da justiça: Filosofia política para além de liberalismo e comunitarismo [1994]. Tradução de Denilson Luis Werle. São Paulo, SP: Boitempo.

. (2012). The right to justification: Elements of a constructivist theory of justice. Translated by Jeffrey Flynn [2007]. New York: Columbia University Press.

. (2011). Kritik der Rechtfertigungsverhältnisse: Perspektiven einer kritischen Theorie der Politik. Berlin: Suhrkamp.

- (2014). Justification and critique: Towards a critical theory of politics. Translated by Ciaran Cronin. Cambridge: Polity Press.

- (2015a). Normativität und Macht: zur Analyse sozialer Rechtfertigungsordnungen. Berlin: Suhrkamp.

. (2015b). The right to justification: Moral and political, transcendental and historical: reply to Seyla Benhabib, Jeffrey Flynn and Matthias Fritsch. Political Theory, 43(6), pp. 46-61.

. (2015c). A critical theory of politics: Grounds, method and aims. Reply to Simone Chambers, Stephen White and Lea Ypi. Philosophy and Social Criticism, 41(3), pp. 225-34.

. (2018). Noumenal power revisited: Reply to critics. Journal of Political Power, 11(3), pp. 294-321.

Habermas. J. (1995). Theorie des kommunikativen Handelns: zur Kritik der funktionalistischen Vernunft [1981]. Band 2. Frankfurt am Main: Suhrkamp.

Honneth, A. (2011). Das Recht der Freiheit: Grundriß einer demokratischen Sittlichkeit. Frankfurt am Main: Suhrkamp.

Jaeggi, R. (2015). O que há (se de fato há algo) de errado com o capitalismo? Três vias de crítica do capitalismo [2013]. Cadernos de Filosofia Alemã, 20(2), pp.13-36.

Melo, R. (2013). Crítica e justificação em Rainer Forst. Cadernos de Filosofia Alemã, 22, pp. 11-30.

Rawls, J. (2005). Political liberalism [1993]. Expanded edition. New York: Columbia University Press. 